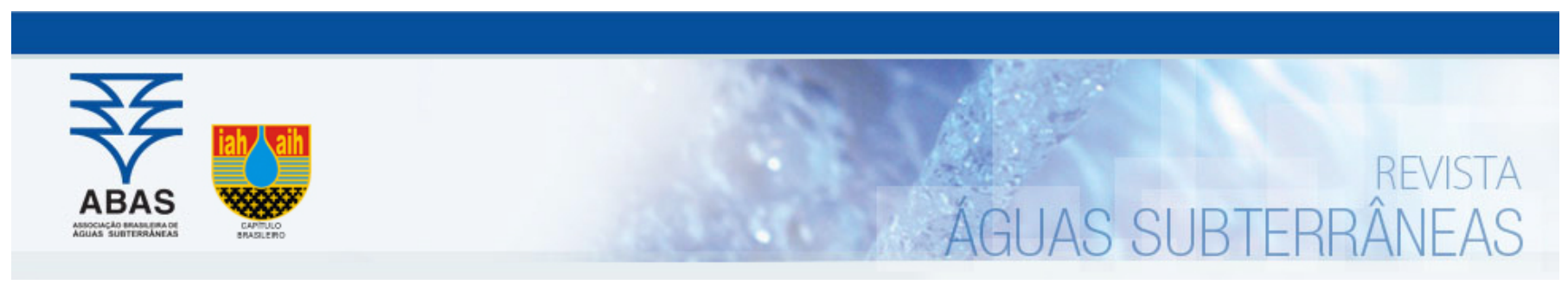

Artigos

\title{
Avaliação do abrandamento de água calcária utilizando hidróxido de cálcio e carbonatação
}

\section{Evaluation of limestone water softening using calcium hydroxide and carbonation}

\author{
Hermes Marcal da Silva ${ }^{1}$; Francinete Veloso Duarte ${ }^{1}$; Agda Louredo Gonçalves Oliveira ${ }^{1}$ \\ 1 Universidade Federal de Minas Gerais (UFMG), Belo Horizonte, MG, Brasil.
}

$\bowtie$ hermesmarcal@hotmail.com; francivel@hotmail.com; agdaloureiro@gmail.com

\begin{tabular}{|c|c|}
\hline & Resumo \\
\hline $\begin{array}{l}\text { Palavras-chave: } \\
\text { Qualidade da água. } \\
\text { Dureza da água. } \\
\text { Gás carbônico. }\end{array}$ & $\begin{array}{l}\text { A água é um recurso fundamental para a vida na terra e a sua qualidade define seus diversos usos. A qualidade da água é } \\
\text { entendida como resultado das ações antrópicas e da sua interação com o meio físico. Assim a água possui características } \\
\text { físicas, químicas e biológicas em virtude de suas propriedades de solvente e de sua capacidade de transportar partículas. } \\
\text { Dentre as características químicas está a dureza de carbonatos que representa a concentração de íons como o cálcio e o } \\
\text { magnésio em solução. Esses íons estão presentes na água subterrânea através de processos de intemperismo químico que } \\
\text { dependem do tempo de contato entre a água e a rocha, temperatura, CO2 disponível e da presença de ácidos orgânicos e } \\
\text { inorgânicos. Em níveis elevados de dureza total a água apresenta um sabor diferenciado o que pode ser desagradável ao } \\
\text { paladar das pessoas. O objetivo desse trabalho é verificar o abrandamento da concentração dos carbonatos de cálcio e } \\
\text { magnésio, pela dissolução de gás carbônico e hidróxido de cálcio, alterando o equilíbrio do sistema carbonato. Foram testa- } \\
\text { das a água carbonatada, água carbonatada e aerada e a água natural com cinco concentrações de hidróxido de cálcio (0, } \\
25,50,75 \text { e } 150 \text { mg L-1). O parâmetro avaliado foi a dureza de carbonatos. Os experimentos foram configurados em fatorial } \\
\text { com dois fatores, aplicou-se o teste Tukey a um nível de } 1 \% \text { de significância. Os resultados mostraram que o fator água e o } \\
\text { fator concentração de hidróxido foram significativos a } 1 \% \text { de significância, já a interação dos dois fatores não. Contudo o } \\
\text { melhor resultado na remoção da dureza foi na concentração de } 150 \mathrm{mg} \text { L-1 de hidróxido de cálcio em água carbonatada e } \\
\text { aerada. }\end{array}$ \\
\hline
\end{tabular}

Keywords:

Water quality.

Carbonate hardness.

Carbon dioxide.

Revisado por pares.

Recebido em: 18/05/2017.

Aprovado em: 02/08/2017.

\begin{abstract}
Water is a fundamental resource for life on earth and its quality defines its various uses. Water quality is known as the result from human actions and from its interaction with the physical environment. Thus water has physical, chemical and biological characteristics because of its solvent properties and its ability to carry particles. Among the chemical characteristics is the carbonate hardness that represents the ion concentration such as calcium and magnesium in solution. These ions are present in groundwater through of chemical weathering processes that depended on the contact time between water and rock, temperature, available $\mathrm{CO} 2$ and presence of organic and inorganic. At high levels of carbonate hardness the water has a different flavor that may be unpleasant to people. The aim of this paper is to verify the decreased concentration of calcium and magnesium carbonates by the dissolution of carbon dioxide and calcium hydroxide, changing the balance of the carbonate system. Carbonated water, carbonated and aerated water, and natural water were tested with five concentrations of calcium hydroxide $(0,25,50,75$ e $150 \mathrm{mg} \mathrm{L-1})$. The evaluated parameter was the carbonate hardness. The experiments were set up in factorial with two factors; the Tukey test was applied at a $1 \%$ significance level. The results showed that the water factor and the hydroxide concentration factor were significant at $1 \%$ of significance, but not the interaction of both factors. However the best result in the hardness removal was the concentration of $150 \mathrm{mg} \mathrm{L-1}$ of calcium hydroxide in carbonated and aerated water.
\end{abstract}

DOI: http://dx.doi.org/10.14295/ras.v31i4.28871

\section{INTRODUÇÃO}

A água é um recurso inorgânico de fundamental importância para a manutenção da vida na terra além de estar presente em quantidades consideráveis como constituinte da matéria viva. Diante disso, surge a preocupação com a qualidade da água que na visão da engenharia ambiental está relacionado às várias partículas e impurezas dissolvidas ou em suspensão presentes na água em virtude de suas propriedades de solvente e da sua capacidade de transportar partículas. Com isso, a qualidade da água é entendida como sendo suas características físicas, químicas e biológicas, como resultado de suas interações com o ambiente natural e com as ações antrópicas (SPERLING, 2005).
Segundo Libânio (2010), os parâmetros físicos englobam a temperatura, a cor, a turbidez, o sabor e odor e condutividade elétrica. Os parâmetros químicos englobam o $\mathrm{pH}$, a alcalinidade, a acidez, a dureza, o oxigênio dissolvido, a salinidade, as demandas químicas e bioquímica de oxigênio, o carbono total, os compostos orgânicos, o ferro e manganês, o nitrogênio, o fosforo, os fluoretos, os metais pesados, o arsênio e os agrotóxicos. Já os parâmetros biológicos tratam das bactérias coliformes, as algas e cianobactérias, os protozoários, os vírus entéricos e comunidades hidrobiológicas. Dentre esses parâmetros a dureza é frequente em áreas com a presença de rochas calcarias, e ela se manifesta pela resistência à reação de saponificação e ainda 
dependendo de sua concentração é perceptível ao paladar da população. De acordo com a Portaria n 2914 de 12 de dezembro de 2011 do Ministério da Saúde, a dureza máxima permitida para atender os padrões de potabilidade é de 500 ppm em carbonato de cálcio ( $\left.\mathrm{CaCO}_{3}\right)$. Em indústrias que utilizam caldeiras, a água dura com concentração de $\mathrm{CaCO}_{3}$ acima de 150 ppm provoca deposição de carbonato de cálcio quando em temperaturas elevadas prejudicando os processos industriais.

Os corpos d'águas naturais como rios, oceanos e lençóis freáticos estão sujeitos a reações químicas com a matéria que os envolvem. Essas interações ácido-base geralmente são as que propiciam a variação do $\mathrm{pH}$ e das concentrações de íons dessas águas. Um exemplo dessas interações é a dissolução do $\mathrm{CO}_{2}$ atmosférico na água formando $\mathrm{O}_{2} \mathrm{H}_{2} \mathrm{CO}_{3}$ e este pode dissociar-se em $\mathrm{H}^{+}$e $\mathrm{HCO}_{3}$ que confere a água poder de dissolver sais e disponibilizar partículas em solução. Assim a presença de certos íons como o cálcio na água se dá, principalmente, pela dissolução do sal $\mathrm{CaCO}_{3}$ em decorrência da diminuição do pH causado pela formação de $\mathrm{H}_{2} \mathrm{CO}_{3}$ na água. Esse $\mathrm{CaCO}_{3}$ é proveniente basicamente de rochas calcárias em contato com a água, que apesar de ser pouco solúvel em água é responsável pela maior ocorrência dos íons $\mathrm{CO}_{3}{ }^{2-}$ e $\mathrm{Ca}^{2+}$. Essas reações de dissolução do $\mathrm{CO}_{2}$ e do $\mathrm{CaCO}_{3}$ não acontecem isoladamente no meio ambiente e sim simultaneamente com outras reações formando o equilíbrio entre a água, o $\mathrm{CaCO}_{3}$ e o $\mathrm{CO}_{2}$ atmosférico ou equilíbrio carbonato (BAIRD, 2002; CANN, 2011).

Pesquisas baseadas nas reações de equilíbrio e nas relações entre o carbonato de cálcio e o dióxido de carbono utilizam a dissolução do $\mathrm{CO}_{2}$ como forma de obter o carbonato de cálcio por precipitação química. Esses estudos visam tanto melhorar a qualidade do carbonato de cálcio precipitado, utilizado na indústria, como reduzir os índices de dureza em águas calcárias. Souto (2008), diz que altas concentrações de dióxido de carbono e hidróxido de cálcio contribuem para a qualidade do carbonato de cálcio precipitado aumentando sua área especifica. Outras pesquisas, no âmbito de retirar e utilizar o dióxido de carbono da atmosfera de forma a aprisiona-lo sob a forma mineral são desenvolvidas. De acordo com Amancio (2007), o aumento na concentração de $\mathrm{CO}_{2}$ leva a um aumento na taxa de crescimento da alga coralínea representado pela precipitação do carbonato de cálcio reduzindo assim os índices de cálcio da água e do $\mathrm{CO}_{2}$ atmosférico. Já Klunk (2009), obteve 91,7\% de rendimento na precipitação do carbonato de magnésio pela injeção de $\mathrm{CO}_{2}$ em solução contendo íons de magnésio.

Como forma de utilizar o $\mathrm{CO}_{2}$ atmosférico e testar condições experimentais para diminuir o nível de dureza de carbonatos, objetivou-se nesse trabalho avaliar o abrandamento da água calcária utilizando-se diferentes níveis de concentração de hidróxido de cálcio relacionados à água bruta e à água carbonatada.

\section{MATERIAL E MÉTODOS}

A coleta das amostras de água utilizadas, assim como as análises físico-químicas foram realizadas pela COPASA/MG. As amostras são originárias de poço tubular no distrito de Quem Quem de Latitude: $16^{\circ} 00^{`} 35^{\prime}$ S e Longitude: $43^{\circ} 31^{`} 30^{\prime}$ W, no município de Janaúba/MG, armazenadas em galões e levadas para experimentos no Laboratório de Química Analítica do Instituto de Ciências Agrárias (ICA) localizado no campus regional da UFMG em Montes Claros. Todas as análises foram realizadas de acordo com o Standard Methods for the examination of water and waste water 21 st (APHA, 2005).

Foram testados três tipos de água (água carbonatada e aerada, água aerada e água bruta) e um aditivo, o $\mathrm{Ca}(\mathrm{OH}) 2$, em cinco concentrações diferentes (0, 25, 50, 75 e $\left.150 \mathrm{mg} \mathrm{L}^{-1}\right)$. Cada teste foi montado dissolvendo o $\mathrm{Ca}(\mathrm{OH})_{2}$ em 1 litro de água, em triplicata para cada uma das quantidades: 0, 25, 50, 75 e 150 $\mathrm{mg}$ de $\mathrm{Ca}(\mathrm{OH})_{2}$. A carbonatação da água foi realizada pela injeção de $\mathrm{CO}_{2}$ a 20 litros de água, utilizando um injetor poroso cilíndrico de aço inox com $1 \mathrm{~cm}$ de diâmetro e $5 \mathrm{~cm}$ de comprimento, conectado a um cilindro de gás carbônico de 3,4 Kg. Foi utilizado o gás carbônico White Martins com 99,5\% de pureza, a uma vazão de $6 \mathrm{~L} \mathrm{~min}^{-1}$. 0 injetor era posicionado no fundo de um recipiente de vidro de $20 \times 40 \times 40 \mathrm{~cm}$ de dimensões, e o gás era injetado até o $\mathrm{pH}$ ficar constante, $\mathrm{pH}$ de saturação em torno de 5,5 (DUARTE, 2010). O recipiente era equipado com uma saída contendo um registro para retirada de alíquotas.

A aeração foi realizada, no mesmo recipiente utilizado na carbonatação, o ar era injetado através de um compressor de ar conectado, por mangueiras de silicone, a um sistema de injetores porosos de sílica, de $15 \mathrm{~cm}$ de comprimento, do tipo usado em aquários, cobrindo todo o fundo do recipiente. A aeração também era realizada até o $\mathrm{pH}$ ficar constante. A água carbonatada e aerada, recebia a aeração imediatamente após a carbonatação.

Cada alíquota de 1 litro era retirada após o tratamento gasoso e colocada em béqueres com o auxílio de uma proveta. A partir de então os testes com o aditivo, $\mathrm{Ca}(\mathrm{OH})_{2}$ eram montados, em triplicata, nas concentrações adequadas imediatamente após o tratamento(s) da água. O fluxograma do experimento é apresentado na figura 1. 
Figura 1 - Fluxograma do experimento

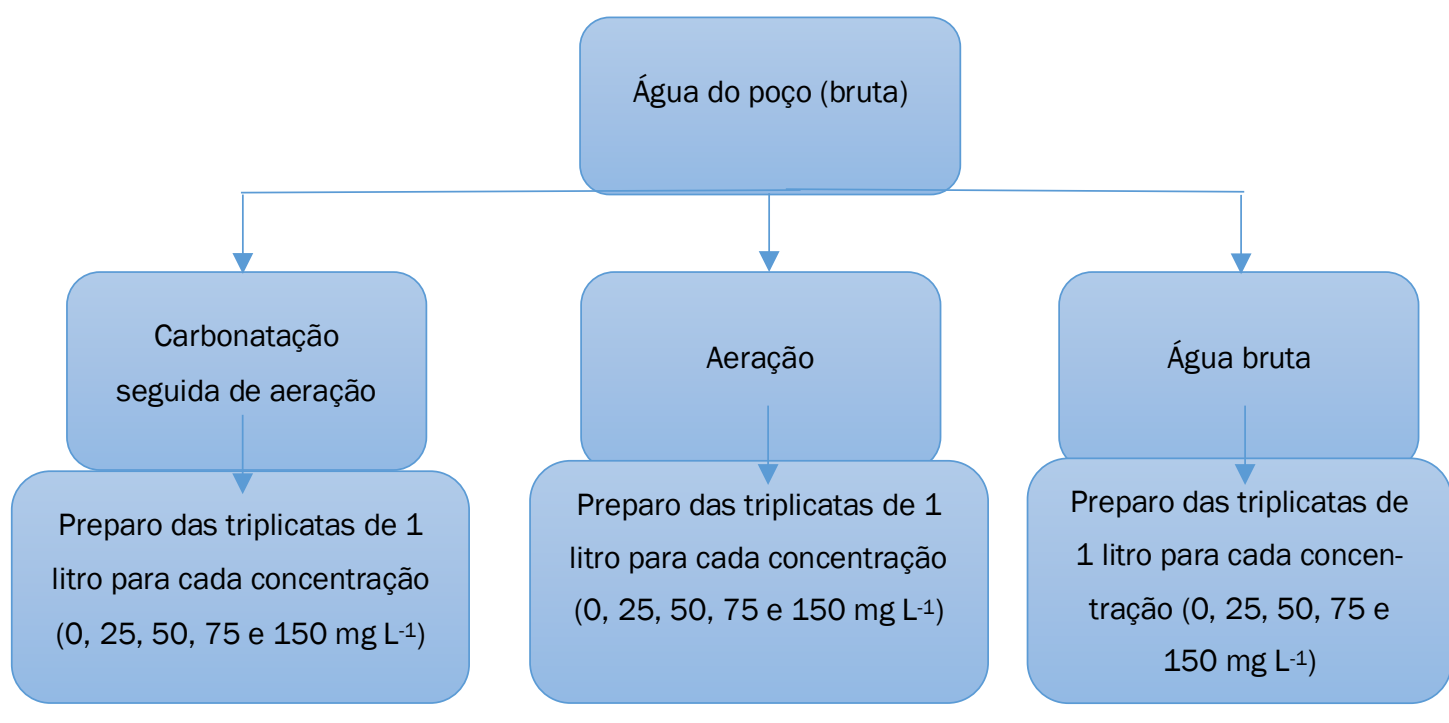

Cada quantidade de hidróxido de cálcio foi adicionada a cada alíquota de 1 litro dos tipos de água e formando assim os testes. Após a adição do hidróxido de cálcio às alíquotas, essas eram homogeneizadas em agitador magnético, sob agitação por 5 minutos na rotação máxima.

Ao final da homogeneização em cada teste as mesmas eram colocadas em repouso por período de 2 horas. E só depois passavam por filtração a vácuo, utilizando papel de filtro de porosidade $45 \mu \mathrm{m}$ e assim os valores de dureza de carbonatos da água de cada teste eram determinados. Para a determinação da dureza total utilizou-se a titulometria (APHA, 2005).

0 experimento se deu com dois fatores sendo quinze tratamentos e três repetições. Para apresentar os resultados utilizou-se gráficos com as médias dos valores de cada tratamento. Foi realizada a análise estatística aplicando-se o teste Tukey a um nível de significância 1\%. 0 software utilizado foi o SISVAR (FERREIRA, 2008). O cálculo das taxas de remoção de dureza de cada tratamento é mostrado a seguir na Equação 1.

$$
\mathrm{Tx}=100 *\left(\mathrm{Di}_{\mathrm{i}}-\mathrm{Dn}\right) / \mathrm{Di}
$$

$D_{i}=$ dureza de carbonato inicial da água em ppm.

$\mathrm{D}_{\mathrm{n}}=$ média das durezas de carbonato obtidas no tratamento $\mathrm{n}$ em ppm.

$\mathrm{N}=$ refere-se aos tratamentos

$\mathrm{Tx}=$ taxa de redução da dureza em porcentagem.

\section{RESULTADOS E DISCUSSÃO}

0 resultado da análise físico-química da água bruta, Tabela 1 , indica uma água muito dura (dureza total $>300$ ppm), com dureza total em 528 ppm sendo esta acima do limite máximo estabelecido pela Portaria 2914 de dezembro de 2011, isto é, fora do padrão de potabilidade, mesmo com os outros parâmetros atendendo aos limites estabelecidos pela portaria 2914.

Os resultados da ANOVA mostram que houve interação significativa a $1 \%$ para o fator águas e para o fator concentrações, como mostra a Tabela 2.

Tabela 1 - Análise físico-química da água do poço do distrito de Quem Quem.

\begin{tabular}{ccc}
\hline Parâmetros & Unidades & Resultados \\
\hline Alumínio & $\mathrm{mg} \mathrm{L}^{-1}$ & $<0,1$ \\
Cloretos & $\mathrm{mg} \mathrm{L}^{-1}$ & 129 \\
Condutividade Elétrica & $\mathrm{Ms} \mathrm{cm}^{-1}$ & 1172 \\
Cor Aparente & $\mathrm{uH}$ & 0,4 \\
Dureza Total & $\mathrm{mg} \mathrm{L}^{-1}$ & 528 \\
Ferro Total & $\mathrm{mg} \mathrm{L}^{-1}$ & $<0,1$ \\
Fluoretos & $\mathrm{mg} \mathrm{L}^{-1}$ & 0,37 \\
Manganês Total & $\mathrm{mg} \mathrm{L}^{-1}$ & $<0,1$ \\
Nitratos & $\mathrm{mg} \mathrm{L}^{-1}$ & 9,48 \\
pH & & 6,9 \\
Sulfatos & $\mathrm{mg} \mathrm{L}^{-1}$ & 57,3 \\
Turbidez & $\mathrm{u} \mathrm{T}$ & 0,27 \\
\hline
\end{tabular}

Fonte: COPASA/MG 
Tabela 2 - Resultado da ANOVA para os testes de dureza

\begin{tabular}{|c|c|c|c|c|c|}
\hline FV & GL & SQ & QM & Fc & $\mathrm{Pr}>\mathrm{Fc}$ \\
\hline Águas & 2 & $98.342,39604$ & 49171,19802 & 44,161 & $0.0000 *$ \\
\hline Concentrações & 4 & 86318,20488 & 21579,55122 & 19,381 & $0.0000 *$ \\
\hline Águas x Concentrações & 8 & 5233,291093 & 654,161387 & 0,588 & 0.7801 \\
\hline Erro & 30 & 33403,95467 & 1113,465156 & & \\
\hline CV (\%): & 8,29 & & & & \\
\hline
\end{tabular}

Média geral:

402,517

**valores $\mathrm{Pr}>\mathrm{Fc}$ iguais ou menores que 0,01(*) indicam diferença significativa ao nível de 1\%. CV e média geral correspondem à variável dureza final; GL: Graus de liberdade; SQ: soma de quadrados; QM: quadrados médios; Fc: Teste de Fisher; Pr>Fc: probabilidade.

0 desdobramento dos fatores, feito pelo teste Tukey a $1 \%$ de probabilidade, mostrou que os tratamentos que obtiveram meIhores resultados foram os que utilizaram o hidróxido de cálcio associado a uma água carbonatada e aerada, Já os tratamentos que obtiveram piores resultados na redução da dureza de carbonatos foram aqueles que utilizaram o hidróxido de cálcio em água sem nenhum tratamento gasoso, o que pode ser observado na tabela 3 .

Tabela 3 - Média das triplicatas dos valores de dureza total para cada tipo de água nas várias concentrações de $\mathrm{Ca}(\mathrm{OH})_{2}$

\begin{tabular}{cccc}
\hline Concentrações & Água carbonatada e aerada & Água aerada & Água bruta \\
\hline 0 & 394 & 482 & 528 \\
25 & 377 & 404 & 488 \\
50 & 336 & 407 & 464 \\
75 & 334 & 378 & 441 \\
150 & 297 & 319 & 389 \\
\hline
\end{tabular}

Os valores apresentados na tabela 3 foram utilizados para a determinação da taxa de remoção da dureza de carbonatos, pela equação 1. Na Figura 2 estão apresentadas as taxas de remo- ção da dureza de carbonatos em função dos tipos de água utilizados (carbonatada e aerada; aerada e natural) e dos níveis de concentrações de $\mathrm{Ca}(\mathrm{OH}) 2(0,25,50,75$ e $150 \mathrm{mg} \mathrm{L-*})$.

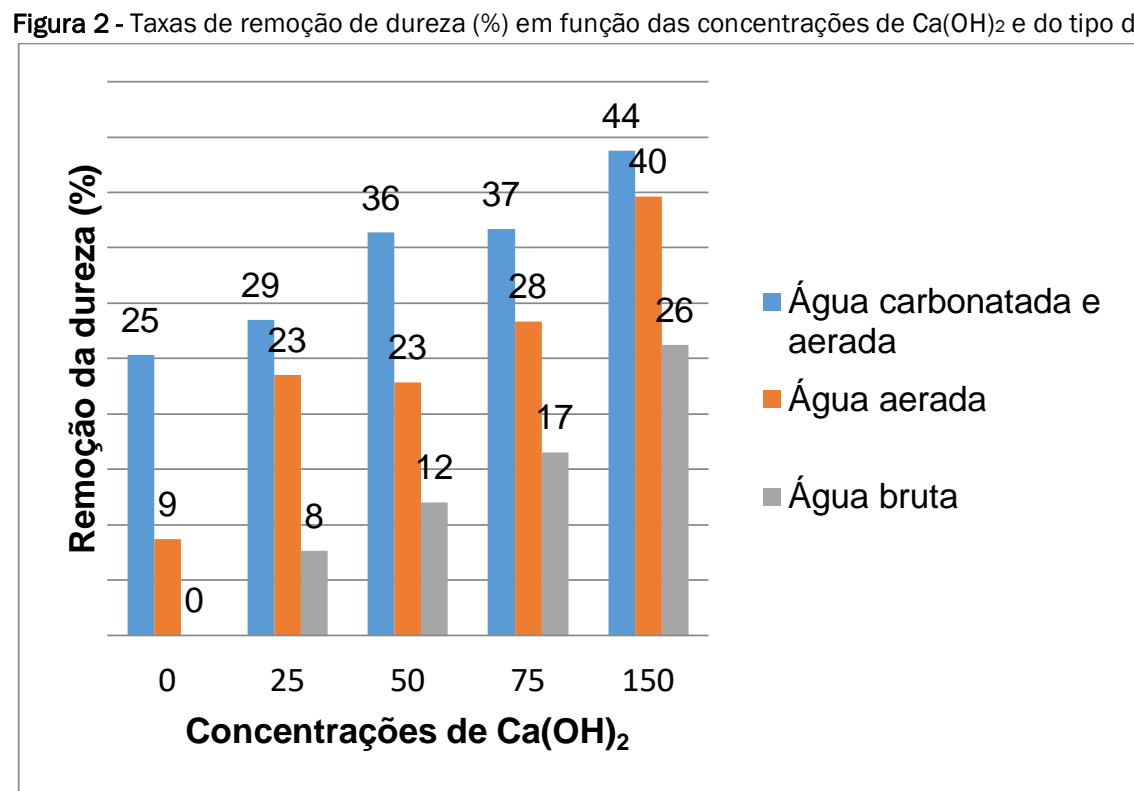

Fonte: Elaborado pelos Autores (2016)

De acordo com os resultados apresentados na Figura 2, a taxa de redução da dureza chegou a um valor de $44 \%$ em comparação com a dureza inicial da água, de 528 ppm em CaCO3. A menor taxa de redução da dureza ocorreu nos tratamentos que receberam $0 \mathrm{mg} \mathrm{L}^{-1}$ e $25 \mathrm{mg} \mathrm{L}^{-1}$ de $\mathrm{Ca}(\mathrm{OH})_{2}$, em água bruta e aerada respectivamente.
Pela Figura 2 observa-se uma eficiência na redução da dureza de carbonatos pelo uso do processo de carbonatação e aeração da água. Com o uso desse tipo de água, a relação entre a taxa de redução da dureza e as concentrações de $\mathrm{Ca}(\mathrm{OH})_{2}$ se mostrou diretamente proporcional. 0 resultado mais expressivo foi na concentração de $150 \mathrm{mg} \mathrm{L-1}$. 
Foi observado que para os três tipos de água, o aumento da concentração do $\mathrm{Ca}(\mathrm{OH})_{2}$ representou uma redução do nível de dureza constatado pela significância estatística desse fator a um nível de significância de 1\%. Resultados semelhantes foram constatados por Dey, Herzog e Srinivasan (2007), que aumentando em até $90 \%$ da quantidade estequiométrica do $\mathrm{CaO}$ obtiveram redução na dureza total, porém para valores acima de $120 \%$ na quantidade estequiométrica a dureza de carbonatos aumentou em 77 ppm.

Nos tratamentos em que a água foi carbonatada e aerada a eficiência na remoção da dureza de carbonatos pode ser explicada pela mineralização do $\mathrm{CO}_{2}$ que quando dissolvido em água forma o ácido carbônico que se dissocia nos íons $\mathrm{H}^{+}$e $\mathrm{HCO}_{3}$. A maior concentração de bicarbonato na solução associada ao hidróxido de cálcio tende a deslocar a reação de equilíbrio entre bicarbonato e cálcio formando o carbonato de cálcio, pouco solúvel em água (BAIRD, 2002).

$$
\mathrm{Ca}^{+2}+2 \mathrm{HCO}_{3}+\mathrm{Ca}(\mathrm{OH})_{2} \longrightarrow 2 \mathrm{CaCO}_{3} \downarrow+2 \mathrm{H}_{2} \mathrm{O}
$$

As Figuras 3 e 4 a seguir ilustram os resultados da análise de regressão linear entre as concentrações de hidróxido de cálcio e os respectivos valores de dureza da solução após os testes em água carbonatada e aerada e em água apenas aerada respectivamente.

Figura 3 - Análise de regressão linear entre hidróxido de cálcio e os valores de dureza obtidos em água carbonatada e aerada

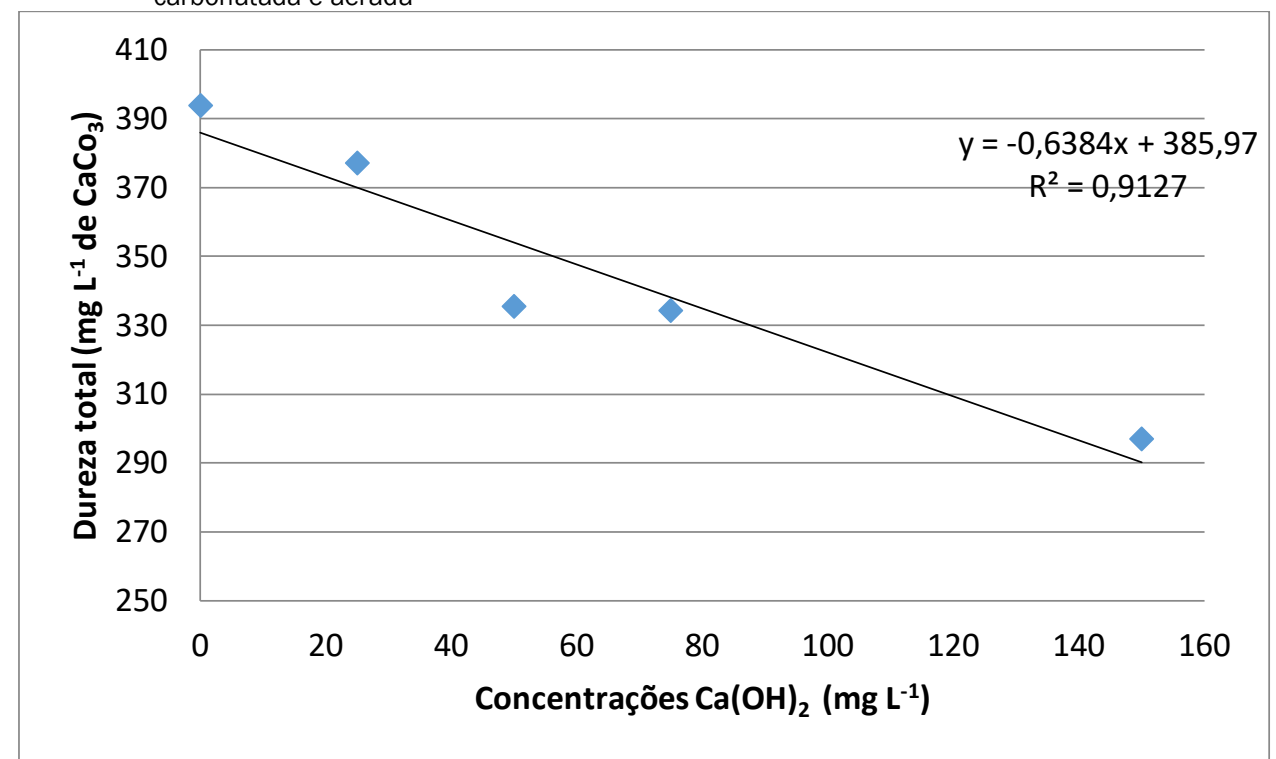

Fonte: Elaborado pelos autores (2016)

Figura 4 - Análise de regressão linear entre hidróxido de cálcio e os valores de dureza obtidos em água aerada

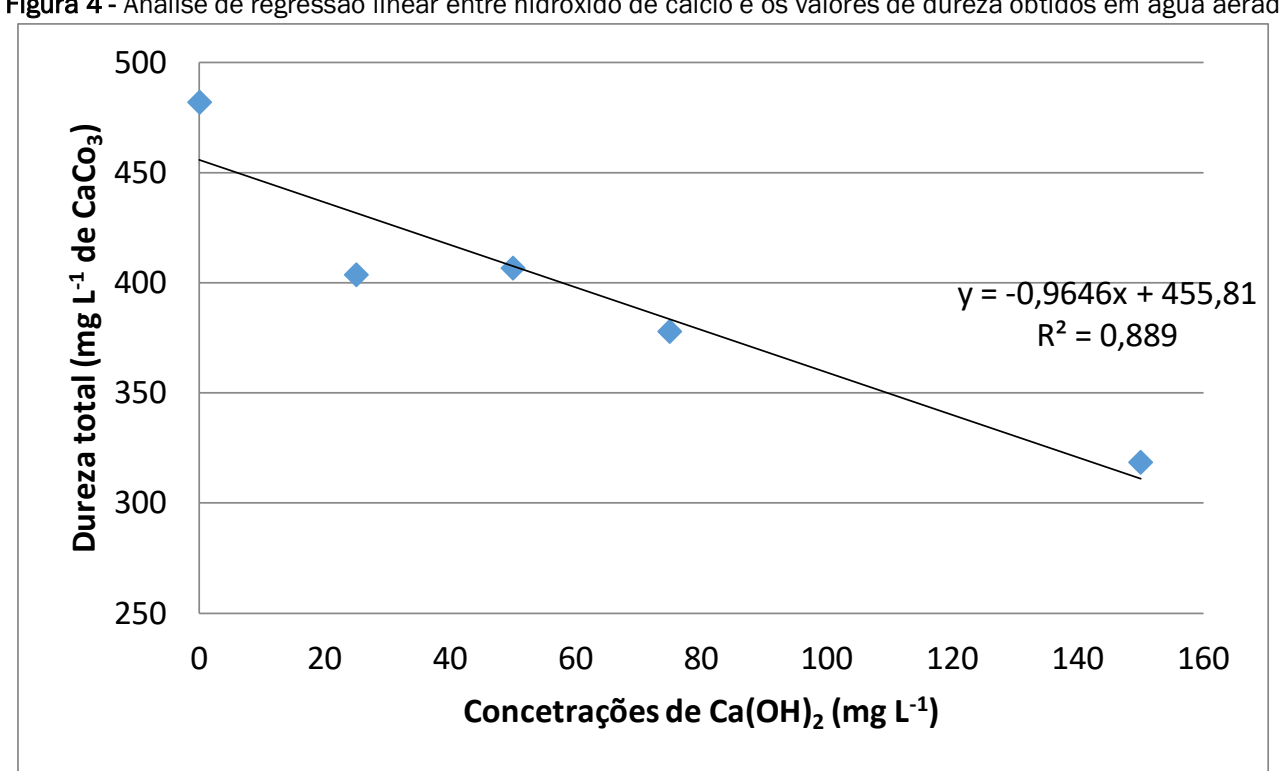

Fonte: Elaborado pelos autores (2016)

0 valor da dureza inicial nos tratamentos que levaram $0 \mathrm{mg} \mathrm{L-1}$ de hidróxido de cálcio foi diferente entre os experimentos com água carbonatada e aerada e com água aerada conforme as figuras 3 e 4 . Esse fato mostra que a tanto a injeção de gás car- bônico seguida da aeração quanto apenas a aeração já altera o valor da dureza de carbonatos da água-bruta, uma vez que a determinação da dureza foi feita após o processo de injeção de gás carbônico e injeção de ar. Entretanto observa-se que a car- 
bonatação seguida da aeração, mesmo sem a adição de $\mathrm{Ca}(\mathrm{OH})_{2}$, leva a uma maior redução da dureza de carbonatos.

A partir da análise da curva de regressão pode-se observar que há uma relação entre a dureza de carbonatos da água e as concentrações de hidróxido de cálcio sendo que nas duas situações tem-se a reta decrescente evidenciando que há remoção da dureza de carbonatos especialmente nas concentrações de 75 e 150 mg L-1. Observa-se também um elevado valor do coeficiente de determinação $\left(\mathrm{r}^{2}\right)$ sendo que o maior valor está no tratamento em que a água foi carbonatada e aerada isso evidencia também uma relação entre a remoção da dureza de carbonatos com o tipo de tratamento gasoso que a água recebe.

\section{CONCLUSÕES}

A partir dos resultados obtidos, pode-se concluir que:

A taxa de redução da dureza de carbonatos variou com os tipos de água e com as concentrações de $\mathrm{Ca}(\mathrm{OH})_{2}$.

Há uma relação proporcional entre a remoção da dureza de carbonatos e as variações da concentração de hidróxido de cálcio independente do tipo de água, porém a eficiência é maior nos experimentos em que há o tratamento gasoso especialmente no que recebe dióxido de carbono mais aeração.

0 tratamento que obteve melhor resultado na redução da dureza de carbonatos foi a água carbonatada e aerada com 150 $m g \mathrm{~L}^{-1}$ de $\mathrm{Ca}(\mathrm{OH})_{2}$, chegando a uma redução de $44 \%$.

\section{REFERÊNCIAS}

APHA; AWWA; WEF. Standard methods for the examination of water and wastewater. 21 ed.. Washington: APHA, 2005.
AMANCIO, C. E. Precipitação de $\mathrm{CaCO}_{3}$ em algas marinhas calcária e balanço de $\mathrm{CO}_{2}$ atmosférico: os depósitos calcários marinhos podem atuar como reservas planetárias de carbono?. 2007. 47f. Dissertação (Mestrado em Ciências) - Instituto de Biociências, Universidade de São Paulo, São Paulo, 2007. Disponível em: < http://www.teses.usp.br/teses/disponiveis/41/41132/tde-06112007-144852/publico/Carlos_Eduardo_Amancio.pdf>. Acesso em: 07 julho 2016.

BAIRD, C. Química ambiental. 2. ed. Porto Alegre: Bookman, 2002.

DEY, D.; HERZOG, A.; SRINIVASAN, V. Chemical precipitation: water softening. 2007. Disponível em: < http://www.egr.msu.edu/ hashsham/courses/ene806/docs/Water\%20Softening\%201.pdf>. Acesso em: 08 junho 2016.

DUARTE, F. V. Influência da aplicação de gás carbônico na redução de precipitação de carbonatos em sistema de irrigação localizada. 2010. 102f. Tese (Doutorado em saneamento, meio ambiente e recursos hídricos) - Programa de pós-graduação, UFMG, Belo Horizonte, 2010. Disponível em: <http://www.smarh.eng.ufmg.br/defesas/531D.PDF>. Acesso em: 03 junho 2016.

FERREIRA, Daniel Furtado. SISVAR: um programa para análises e ensino de estatística. Revista Symposium, Lavras, v. 6, p. 36-41, 2008.

LIBÂNIO, M. Fundamentos de qualidade e tratamento de água. 3. ed. Campinas: Editora Átomo, 2010. 494p.

SOUTO, E. C. S. Estudo de condições operacionais para obtenção de carbonato de cálcio precipitado. 2008. 77f. Dissertação (Mestrado em engenharia química) - Programa de pós-graduação, UFU, Uberlândia, 2008. Disponível em: < https://repositorio.ufu.br/bitstream/123456789/15107/1/Eliane.pdf>. Acesso em: 22 junho 2016.

SPERLING, M. V. Introdução à qualidade das águas e ao tratamento de esgotos. 3. ed. Belo Horizonte: UFMG, 2005. 452p.

KLUNK, M. A. Sequestro de $\mathrm{CO}_{2}$ sob a forma mineral: precipitação de carbonato de magnésio. 2009. 63f. Dissertação (Mestrado em engenharia e tecnologia dos materiais) - Programa de pós-graduação, Pontifícia Universidade Católica do Rio Grande do Sul, Rio Grande do Sul, 2009. Disponivel em: < http://repositorio.pucrs.br/oai/request?verb=ListRecords\&metadataPrefix =oai_dc\&set=col_10923_347>. Acesso em: 15 julho 2016. 